kín khít là $83.5 \%$, hình thể là $93.2 \%$. Theo dõi sau 3 tháng, 6 tháng: Không miếng trám nào có sâu tái phát. $100 \%$ trẻ hai lòng khi được điều trị theo phương pháp này.

\section{TÀI LIÊU THAM KHẢO}

1. Ismail AI, Sohn $\mathbf{W}$, Tellez $M$, et al. The International Caries Detection and Assessment System (ICDAS): an integrated system for measuring dental caries. Community Dent Oral Epidemiol. 2007;35(3):170-178. doi:10.1111/j.1600-0528.2007.00347.x

2. OäNAL B, Pamir T. The two-year clinical performance of esthetic restorative materials in noncarious cervical lesions. The Journal of the American Dental Association. 2005;136(11):15471555. doi:10.14219/jada.archive.2005.0085

3. A.Phonghanyudh,

P.Phantumvanit, Y.Songpaisan. Clinical evaluation of three caries removal approaches in primary teeth: A randomised controlled trial. Community Dental Health. 2011:1-6.

4. Kim Sun-Cook. Development of School-based Oral Health Program in Emerging Countries.2014.

5. Zhao IS, Gao SS, Hiraishi N, et al. Mechanisms of silver diamine fluoride on arresting caries: a literature review. Int Dent J. 2018;68(2):67-76. doi: 10.1111 /idj.12320

6. Đố Châu Giang. Kết Quả Trám Xoang Sâu Loại I Bằng Kỹ Thuật Trám Răng Không Sang Chấn Cải Tiến ở Trẻ 5 Tiuổi Tại Một Số Trương Mâuu Giáo Hà Nôi Năm 2018.; 2018.

7. Bùi Bảo Ngọc (2015), Đánh giá kết quả trám răng không sang chấn trên răng hàm sữa học sinh 7-9 tuổi bằng Fuji VII tại trường Hermann Gmeiner Hà Nội, Khoá luận tốt nghiệp bác sĩ y khoa, trường Đại học Y Hà Nội.

8. Nguyễn Hữu Huynh (2013), Nhận xét thực trạng bệnh sâu răng, viêm lợi cúa trẻ 3 - 5 tuổi tại Trường mấu giáo Hữu nghi Việt - Triều Hà Nối năm 2013, Luận văn tốt nghiệp đại học, Trường Đại học Y Hà Nội.

\title{
ĐÁNH GIÁ KẾT QUẢ PHẪU THUÂTT NộI SOI QUA ĐƯờNG NIẸU ĐẠO CẮT PHÌ ĐẠI LÀNH TÍNH TUYẾN TIỀN LIÊTT BẰNG ĐIỆN LƯớNG CỰC Ở BỆNH NHÂN CÓ BỆNH LÝ TIM MẠCH
}

\section{TÓM TẮT}

Mục tiêu: Đánh giá kết quả phẫu thuật nội soi qua đường niệu đạo cắt phì đại lành tính tuyến tiền liệt bằng điện lưỡng cực ở bệnh nhân có bệnh lý tim mạch. Đối tượng và phướng pháp nghiên cứu: Nghiên cứu mố tả hồi tiến cứu trên 63 bệnh nhân bị u phì đại lành tính tuyến tiền liệt (UPĐLTTTL) có bệnh lý tim mạch kèm theo được điều trị bằng cắt đốt nội soi qua đường niệu đao bằng điện lưỡng cứctai bênh viện Đại Học Y Hà Nội từ tháng 01 năm 2019 đến tháng 5 nắm 2021. Kết quả: NC hôi cứu 63 BN, độ tuổi trung bình là $73.5 \pm 9.1$, bệnh lý tim mạch đồng mắc: tăng huyết áp (THA) $73 \%$, rối loạn nhịp tim $19.1 \%$, bênh mạch vành $9.5 \%$, đặt máy tạo nhịp $6.4 \%, 8$ bệnh nhân dùng thuốc chống đông. Điểm IPSS và Q̀oL trước mổ $22.5 \pm 3.8$ và $4.6 \pm 0.7$, trọng lượng tuyến tiền liệt $68.3 \pm 31.8 \mathrm{~g}$, phân suất tống máu (EF) trên siêu âm tim $68.9 \pm 6.0 \%$. Thời gian phẫu thuật $55.3 \pm$ 21.4 phút, thời gian hậu phẫu $6.4 \pm 2.0$ ngày. Không gặp biến chứng trong mổ. Không có trường hợp nào đau thắt ngực, khó thở hay phải can thiệp tim mạch. Ba trường hợp biến chứng sau mổ: 2 chảy máu và 1 đau tức chân 2 bên, tất cả đều được điều trị nội ổn

\footnotetext{
${ }^{1}$ Bệnh viện đa khoa tỉnh Nam Định

2Trường Đại học Y Hà Nội

Chịu trách nhiệm chính: Đỗ Văn Hưng

Email: drhung23@gmail.com

Ngày nhận bài: 4.6.2021

Ngày phản biện khoa học: 28.7.2021

Ngày duyệt bài: 5.8.2021
}

\section{Đỗ Văn Hưng ${ }^{1}$, Hoàng Long ${ }^{2}$}

định. Tái khám 1 tháng không có trường hợp nào phải nhập viện điều trị về tim mạch, 1 trường hợp tử vong do bệnh phổi tắc nghẽn mạn tính. Kết luận: Phẫu thuât nôi soi qua đường niệu đạo cắt phì đại tiền liệt tuyển bằng điện lưỡng cực (B-TURP) là phương pháp an toàn, hiệu quả trong điều trị phì đại lành tính tuyến tiền liệt trên nhóm bệnh nhân có bệnh lý tim mạch.

Tử khóa: Tăng sản lành tính tuyến tiền liệt, nội soi cắt tuyến tiền liệt qua niệu đạo bằng điện lưỡng cực, nội soi cắt tuyến tiền liệt qua niệu đạo trong nước muối (TURIS).

\section{SUMMARY \\ EVALUATION OF THE RESULTS BIPOLAR \\ TRANSURETHRAL RESECTION OF THE \\ PROSTATE IN PATIENTS TREATMENT BENIGN PROSTATIC HYPERPLASIA WITH CARDIOVASCULAR DISEASE}

Purpose: To evaluation of the results bipolar transurethral resection of the prostate in patients treatment benign prostatic hyperplasia with cardiovascular disease. Materials and methods: A retrospective and prospective study was carried out on 63 patient who were diagnosed with benign prostatic hyperplasia with cardiovascular disease underwent bipolar transurethral resection of the prostate from $01 / 2019$ to $05 / 2021$ at the Department of Urology of Hanoi Medical University Hospital. All the data of patient including clinical and subclinical signes were collected and analyzed. Results: Mean age of the patient was $73.5 \pm 9.1$ years. Accompanying cardiovascular disease: hypertension $73 \%$, arrhythmia 
$19.1 \%$, coronary heart disease $9.5 \%$, pacemaker $6.4 \%$, eight patients taking anticoagulants. IPSS and QoL score preoperative of patients were $22.5 \pm 3.8$ and $4.6 \pm 0.7$ respectively, prostate weight was 68.3 $\pm 31.8 \mathrm{~g}$, ejection fraction (EF) on echocardiography was $68.9 \pm 6.0 \%$. The mean operative time was 55.3 \pm 21.4 min, the mean hospital stay was $6.4 \pm 2.0$ days. No patients had complications during surgery, angina, shortness of breath or cardiovascular intervention. There were 3 patients had postoperative complications: two of bleeding, one of leg pain on both sides, all were treated medically and had good results. One-month follow-up, there were no cases requiring hospitalization for cardiovascular disease. One patient died from chronic obstructive pulmonary disease. Conclusions: Bipolar transurethral resection of the prostate is a safe and effective method for the treatment in patients of benign prostatic hyperplasia with cardiovascular disease.

Keywords: Benign prostatic hyperplasia, bipolar transurethral resection of the prostate (B-TURP), transurethral resection of the prostate in saline (TURIS).

\section{I. ĐẶT VẤN ĐỀ}

Tăng sản lành tính tuyến tiền liệt (BPH) là một bệnh lý phổ biến trên toàn thế giới, là sự tăng sản các thành phần tế bào của tuyến tiền liệt bao gồm tế bào biểu mô và mô đệm của tuyến tiên liệt [1]. BPH thường gặp ở nam giới trên 50 tuổi, tuổi càng cao thì tỷ lệ mắc các bệnh lý kèm theo như: tim mạch, hố hấp, chuyển hóa... càng nhiều. Các bểnh lý nền càng làm nặng thêm tình trạng đi tiểu và ảnh hưởng tới việc lựa chọn phương pháp điều trị cũng như làm tăng nguy cơtai biến trong và sau phẫu thuật.

Phương pháp cắt nội soi qua niệu đạo bằng điện lưỡng cực (B-TURP) với nhiều ưu điểm hạn chế hội chứng hấp thu nước do dùng dịch rửa Natriclorid 0,9\%, không có dòng điện qua người bệnh nhân trong quá trình phầu thuật, ít chảy máu hơn cắt nội soi bằng điện đơn cực ( $M$ TURP) do khả năng cầm máu tốt đặc biệt trên những bệnh nhân tim mach đang dùng thuốc chống đông [2]... Tại Việt Nam đã có những nghiên cứu về nội soi lưỡng cực điều trị UPĐLTTTL nhưng tính an toàn của nó trên những bệnh nhân có bệnh lý nền tim mạch kèm theo thì chưa được kiểm chứng, từ thực tế trên chúng tôi thực hiện đề tài nghiên cứu "Đánh giá kêt quả phẫu thuật nội soi qua đường niệu đạo cắt u phi đại lành tính tuyến tiền liệt bằng điện lưỡng cực ở bệnh nhân có bệnh lý tim mạch"với hai mục tiêu sau:

1. Mô tả đặc điểm lâm sàng, cận lâm sàng bệnh nhân phi đại lành tính tuyến tiên liệt có bệnh lý tim mạch được phẫu thuật nội soi qua niệu đạo bằng điện lưỡng cực.
2. Đánh giá kêt quả phẫu thuật nội soi qua niệu đạo bằng điện lưỡng cực điều trị phi đại lành tính tuyến tiền liệt ở nhóm bệnh nhân trên.

II. ĐỐl TƯỢNG VÀ PHƯƠNG PHÁP NGHIÊN CỨU

2.1. Đối tượng nghiên cứu: Gồm những bệnh nhân được chẩn đoán, điều trị bằng phẫu thuật nội soi cắt đốt lưỡng cực UPĐLTTTL có kèm theo bệnh lý tim mạch tại bệnh viện đại học Y Hà Nội từ tháng 1/2019 - 5/2021.

2.2. Tiêu chuẩn lựa chọn bệnh nhân: Bệnh nhân được chẩn đoán UPPĐLTTTL có chì định phẫu thuật: Thang điểm IPSS 20 -35 điểm, điểm chất lượng cuộc sống QoL 4-6 điểm, có các biến chứng (bí tiểu tái phát, nhiễm khuẩn đường tiết niệu tái phát, tiểu máu tái phát, sỏi bàng quang, suy thận do trào ngược...), được điều trị bằng phẫu thuật nội soi qua niệu đạo bằng điện lưỡng cực, có bệnh lý tim mạch kèm theo (THA, rối loạn nhịp tim, đặt máy tạo nhịp, suy tim độ IIII theo NYHA, các bệnh lý tim mạch phải duy trì thuốc chống đông), được khẳng định bằng giải phẫu bệnh lý sau mổ là u phì đại lành tính tuyến tiền liệt.

Tiều chuẩn loại trừ: Các trường hợp có chống chỉ định với phẫu thuật nội soi: rối loạn đông máu nặng chưa được kiểm soát, hẹp niệu đạo... bệnh nhân nhiễm khuẩn tiết niệu chưa được điều trị, tiền sử dị ứng thuốc gây mê, gây tê, bệnh lý khớp háng không thể đặt bệnh nhân ở tư thễ sản khoa.

\subsection{Phương pháp nghiên cứu}

Thiết kế nghiên cứu: Theo phương pháp mô tả theo dõi dọc hồi cứu kết hợp tiến cứu.

Chọn mẫu ngẫu nhiên thuận tiện.

Quy trình nghiên cứu: Thu thập các chỉ số lâm sàng, cận lâm sàng, thời gian phẫu thuật, thời gian nằm viện sau mổ, tai biến, biến chứng trong và sau mô.

\section{KẾT QUẢ NGHIÊN CứU}

\subsection{Thông tin chung bệnh nhân}

Bảng 1. Thông tin chungbệnh nhân

\begin{tabular}{|c|c|c|c|}
\hline \multicolumn{2}{|c|}{ Thông tin chung } & $\begin{array}{l}\text { Số bệnh } \\
\text { nhân (n) }\end{array}$ & $\begin{array}{l}\text { Tỷ lề } \\
(\%)\end{array}$ \\
\hline \multirow{4}{*}{ Tuổi } & $<60$ & 5 & 8.0 \\
\hline & $60-69$ & 13 & 20.6 \\
\hline & $70-79$ & 29 & 46.0 \\
\hline & $\geq 80$ & 16 & 25.4 \\
\hline \multicolumn{4}{|c|}{ Tuối trung bình: $73.56 \pm 9.11$} \\
\hline \multirow{4}{*}{$\begin{array}{l}\text { Lý do vào } \\
\text { viện }\end{array}$} & Tiểu khó & 33 & 52.4 \\
\hline & Tiếu đêm nhiêu & 4 & 6.3 \\
\hline & Bí đái & 23 & 36.5 \\
\hline & Tiếu máu & 3 & 4.8 \\
\hline Các bệnh & THA đơn thuân & 28 & 44.4 \\
\hline
\end{tabular}




\begin{tabular}{|c|c|c|c|}
\hline tim mạch & Rối loạn nhịp & 12 & 19.1 \\
\cline { 2 - 4 } kèm theo & Bệnh mạch vành & 6 & 9.5 \\
\cline { 2 - 4 } & Máy tạo nhịp & 4 & 6.4 \\
\cline { 2 - 4 } & Suy tim & 6 & 9.5 \\
\cline { 2 - 4 } & $\begin{array}{c}\text { Mạch máu ngoại } \\
\text { biên }\end{array}$ & 7 & 11.1 \\
\hline $\begin{array}{c}\text { Phân loại } \\
\text { sức khỏe } \\
\text { theo ASA }\end{array}$ & II & 42 & 66.7 \\
\cline { 2 - 4 } Nguy cơ tim & III & 21 & 33.3 \\
\cline { 2 - 4 } mạch & Nhẹ & 49 & 77.8 \\
\hline Thời gian & Dứng trước mốn & 8 & $2.4 \pm 3.4$ \\
\hline
\end{tabular}

\begin{tabular}{|c|c|c|c|}
\hline $\begin{array}{c}\text { chống } \\
\text { đông (ngày) }\end{array}$ & Dùng lại sau mổ & 8 & $4 \pm 1.9$ \\
\hline
\end{tabular}

Tuối trung bình là $73.56 \pm 9.11$, vào viện với lý do đái khó là chủ yếu (52.4\%), bí đái $(36.5 \%)$, có 4 trường hợp đặt máy tạo nhịp $(6.4 \%)$, suy tim $(9.5 \%)$, bệnh mạch vành $(9.5 \%)$, nguy cơ tim mạch mức độ nhe $(77.8 \%)$, trung bình (22.2\%) theo phân loại ACC/AHA [3], có 8 bệnh nhân dùng chống đông, thời gian dừng thuốc chống đông trước mổ là (2.4 33.4$)$ ngày, dùng lại sau mổ là (4 41.9$)$ ngày.

3.3. Lâm sàng, siêu âm.

Bảng 3. Lâm sàng và siêu âm trước mổ

\begin{tabular}{|c|c|c|c|c|c|}
\hline & Chỉ số & n & Trung bình & min & max \\
\hline \multirow{2}{*}{ Lâm } & IPSS & 63 & $22.5 \pm 3.8$ & & \\
\hline \multirow{3}{*}{ Siêu âm } & QoL & 63 & $4.6 \pm 0.7$ & & \\
\cline { 2 - 6 } & Trọng lượng TLT $(\mathrm{g})$ & 63 & $68.3 \pm 31.8$ & 17 & 165 \\
\cline { 2 - 6 } & PVR (ml) & 35 & $47.1 \pm 58.1$ & 0 & 231 \\
\cline { 2 - 6 } & EF (\%) & 63 & $68.9 \pm 6.0$ & 50 & 79 \\
\cline { 2 - 7 } & Giảm vận động vùng & 2 & & & \\
\hline
\end{tabular}

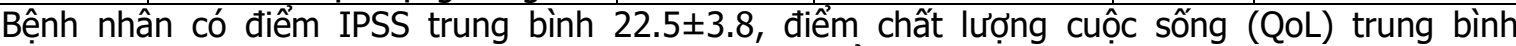

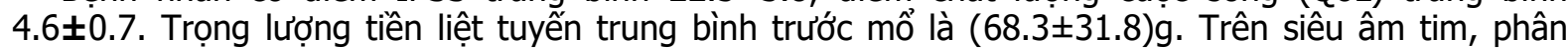
suất tống máu $\mathrm{EF}(\%)$ trung bình $(68.9 \pm 6.0)$, trong đó có 1 trường hợp $(1.6 \%)$ EF giảm $(<55 \%)$, 2 trường hợp trên siêu âm tim có giảm vận động vùng, được chỉ định chụp mạch vành, có hẹp mạch vành nhưng chưa có chỉ định can thiệp mạch vành.

3.4. Đặc điểm liên quan đến điêuu trị

Bảng 5. Một số đặc điểm liên quan đến điều trị

\begin{tabular}{|c|c|c|c|}
\hline Thời gian & $\begin{array}{c}\text { Chung } \\
\text { (n=63) }\end{array}$ & $\begin{array}{c}\text { Nhóm dùng chống } \\
\text { đông (n=8) }\end{array}$ & $\begin{array}{c}\text { Nhóm không dùng } \\
\text { chống đông(n=55) }\end{array}$ \\
\hline Phấu thuật (phút) & $54.9 \pm 21.5$ & $54.9 \pm 18.9$ & $54.9 \pm 22.1$ \\
\hline Truyền rửa bàng quang(ngày) & $3.6 \pm 1.0$ & $4.4 \pm 1.8$ & $3.5 \pm 0.8$ \\
\hline Lưu thông tiếu (ngày) & $4.9 \pm 1.4$ & $6.4 \pm 3.0$ & $4.7 \pm 0.9$ \\
\hline Hậu phầu (ngày) & $6.4 \pm 2.0$ & $7.8 \pm 3.1$ & $6.2 \pm 1.8$ \\
\hline
\end{tabular}

Thời gian phẫu thuật trung bình $54.9 \pm 21.5$ phút, không có sự khác biệt thời gian phẫu thuật giữa nhóm có dùng thuốc chống đông và nhóm không dùng thuốc chống đông $(p=0.501)$. Thời gian lưu sonde tiểu và thời gian hậu phấu của nhóm dùng thuốc chống đông cao hơn so với nhóm không dùng thuốc chống đông, sự khác biệt này không có ý nghĩa thống kê với $\mathrm{p}=0.117$ và $\mathrm{p}=0.216$.

Bảng 6. Tai biến trong mô, biên chứng sớm sau mố

\begin{tabular}{|c|c|c|}
\hline Tai biến, biến chứng & $\begin{array}{c}\text { Số bệnh } \\
\text { nhân } \mathbf{( n )}\end{array}$ & $\begin{array}{c}\text { Tỷ lệ̂ } \\
(\mathbf{\%})\end{array}$ \\
\hline Hội chứng nội soi & 0 & 0 \\
\hline Chảy máu & 2 & 3.2 \\
\hline
\end{tabular}

\begin{tabular}{|c|c|c|}
\hline Truyền máu & 0 & 0 \\
\hline Sốt nhiếm khuẩn & 4 & 6.3 \\
\hline Bí đái sau rút sonde niệu đạo & 3 & 4.8 \\
\hline Đái khó sau nút sonde niệu đạo & 2 & 3.2 \\
\hline Hạ huyết áp & 3 & 4.8 \\
\hline Mạch máu ngoại vị & 1 & 1.6 \\
\hline Can thiệp tim mạch & 0 & 0 \\
\hline
\end{tabular}

Không gặp hội chứng nội soi,trong mổ có 3 hạ huyết áp giảm $\geq 20 \mathrm{mmHg}$ so với bắt đầu phẫu thuật, 2 trường hợp chảy máu sau mổ, không phải truyền máu trong và sau mổ, không có trường hợp nào đau thắt ngực hay khó thở trong và sau mổ, có 1 trường hợp đau tức chân 2 bên sau mổ ở bệnh nhân đãđược chẩn đoán xơ vữa động mạch chi dưới 2 bên trước mổ.

Bảng 8. Kiểm tra sau mổ 1 tháng và thời điểm kêt thúc nghiên cứu

\begin{tabular}{|c|c|c|c|}
\hline Chỉ số & $\begin{array}{c}\text { Trước mố } \\
\mathbf{X} \pm \text { SD (n) }\end{array}$ & $\begin{array}{c}\text { Sau mố 1 tháng } \\
\mathbf{X} \pm \mathbf{S D}(\mathbf{n})\end{array}$ & $\begin{array}{c}\text { Kết thúc NC } \\
\mathbf{X} \pm \mathbf{S D}(\mathbf{n})\end{array}$ \\
\hline Trọng lượng TTL (g) & $68.3 \pm 31.8(63)$ & $40.1 \pm 23.8(55)$ & $31.8 \pm 18.4(21)$ \\
\hline
\end{tabular}




\begin{tabular}{|c|c|c|c|}
\hline PVR (ml) & $47.1 \pm 58.1(35)$ & $20.9 \pm 38.7(55)$ & $6.4 \pm 10.1(21)$ \\
\hline IPSS & $22.5 \pm 3.8(63)$ & $10.3 \pm 3.9(55)$ & $8.0 \pm 4.5(62)$ \\
\hline QoL & $4.6 \pm 0.7(63)$ & $1.96 \pm 0.9(55)$ & $1.6 \pm 0.9(62)$ \\
\hline
\end{tabular}

\section{BÀN LUÂ̂N}

Nghiên cứu của chúng tôi có63 trường hợp đủ tiêu chuẩn tham gia. Tuổi trung bình lúc chẩn đoán là 73.56 99.11.Độ tuổi trong nghiên cứu của chúng tôi cao hơn các tác giả khác [4] [5] [6]. Trong nghiên cứu này bệnh nhân có tiền sử phát hiện bệnh tim mạch từ trước 52/63 $(82.5 \%), 11 / 63$ (17.5\%) bệnh nhân còn lại chưa có tiên sử tim mạch, được phát hiện khi nhập viện. Tất cả các bệnh nhân này được làm $100 \%$ điện tâm đồ, siêu âm tim và khám chuyên khoa tim mach trước phẫu thuật.

Tỉ lệ bệnh nhân bị tăng huyết áp trong nghiên cứu là $73 \%$, cao hơn hẳn so với các nghiên cứu khác [6] [7]. Tăng huyết áp là một yếu tố nguy cơ chính gây ra các biến cố mạch vành, đột quy, suy tim, bệnh động mạch ngoại vi, và là yếu tố làm tăng nguy cở chảy máu trong và sau phẫu thuật, tất cả bệnh nhân tăng huyết áp trong nghiên cứu đều được hội chẩn chuyên khoa tim mạch và điều trị trước mổ, trong mổ không có trường hợp nào chảy máu, hoặc hội chứng nội soi, có 3 trường hợp hạ huyết áp trong mổ (huyết áp giảm $\geq$ $20 \mathrm{mmHg}$ so với trước khi bắt đâuu phẫu thuật) trong đó huyết áp tâm thu trong mổ thấp nhất là $100 \mathrm{mmHg}$, không có trường hợp nào phải sử dụng vận mạch trong và sau mổ.

Đối với trường hợp đặt máy tạo nhịp tim, đã có nhiều báo cáo ảnh hưởng tiều cực của đốt điện đơn cực lên hoạt động của máy tạo nhịp tim trong quá trình phấu thuật TURP [8] [9]. Trong nghiên cứu này được sử dụng năng lượng điện lưỡng cực, dòng điện chỉ đi giữa hai đâuu của dao cắt, khônng có dòng điện qua người bệnh nhân, đã hạn chế yếu tố gây nhiễu với máy tạo nhịp tim. Trong nghiên cứu của chúng tôi có 4 trường hợp đặt máy tạo nhịp vĩnh viễn, các bệnh nhân này được siêu ầm tim và khám chuyên khoa tim mach trước mổ, 2/4 trường hợp được yều cầu kiểm tra hoạt động của máy tạo nhịp trước phẫu thuật, kết quả máy đang hoạt động bình thường, trong quá trình phẫu thuật không ghi nhận trường hợp nào xuất hiên rối loạn điền tim so với trước khi bắt đầu phẫu thuật. Kết quả này cũng tương tự như nghiên cứu Yang.

Đối với trường hợp dùng thuốc chống đông trải qua phẫu thuật nội soi cắt đốt tiền liệt tuyến làm tăng nguy cớ chảy máu trong và sau phẫu thuật, vì thế lựa chọn phương pháp và loại năng lượng nào là cần thiết, có nhiêu nghiên cứu so sánh khả năng cầm máu của TURP đơn cực và lưỡng cực [4][5], cho thấy năng lượng lưỡng cực tốt hơn đơn cực về khả năng cầm máu. Trong nghiên cứu của chúng tôi có 8 bệnh nhân duy trì chống đông trước mổ, Thời gian ngừng thuốc chống đông trước mổ trong nghiên cứu 2,37 \pm 3,44 ngày, thời gian dùng lại trung bình $4,0 \pm 1,85$ ngày. Kết quả không có trường hợp nào chảy máu nghiêm trọng trong và sau phẫu thuật, trong thời gian hậu phẫu có 2 trường hợp chảy máuở BN có tiền sử đặt stent động mạch vành được dùng lại Lovenox sớm sau mổ $24 \mathrm{~h}$ và 48h, bệnh nhân được điều trị nội khoa, điều chỉnh thuốc chống đồng, tăng dung dịch truyền rửa bàng quang, lưu sonde niệu đạo 7 ngày và 8 ngày,không phải truyền máu, tình trạng ổn định ra viện ngày thứ 9 và thứ 10 sau mố. Về diễn biến tim mạch trong thời gian hậu phẫu trên, không có trường hợp nào biểu hiện đau tức ngực hay khó thở, không có trường hợp nào phải can thiệp tim mạch, có 1 trường hợp có biểu hiện tức nhẹ chi dưới 2 bên ở BN có tiển sử xơ vữa động mạch chi dưới 2 bên. Bệnh nhân này đã được hội chẩn lại chuyên khoa tim mạch, siêu âm dopller lại hệ động mạch chi dưới, điều chỉnh lại thuốc chống đông sau mổ, diễn biến tốt, ổn định ra viện ngày thứ 14 sau mổ.

Thời gian phẫu thuật trong nghiên cứu trung bình là $54.9 \pm 21.5$ phút thấp hơn đa số các nghiên cứu khác [5][7], thời gian phẫu thuật giữa nhóm có dùng và không dùng thuốc chống đông là tương đương nhau, trong khi đó thời gian lưu sonde niệu đạo và thời gian hậu phẫu của nhóm dùng thuốc chống đông cao hởn nhóm không dùng chống đông, nhóm dùng chống đông nước truyền rửa bàng quang đỏ hơn nên thời gian truyền rửa bàng quang kéo dài hơn và kéo theo thời gian lưu sonde và thời gian hậu phẫu cũng kéo dài theo.

Kết quả phẫu thuật có $100 \%$ bênh nhân được phẫu thuật thành công, không có bệnh nhân nào phải chuyển phương pháp, không có trường hợp nào mắc hội chứng TURP, không có trường hợp nào chảy máu và phải truyền máu trong mổ, kết quả này tương đương với nghiên cứu khác [5] [6], trong thời gian hậu phẫu không có trường hợp nào xuất hiện đau thắt ngực, khó thở hay phải can thiệp tim mạch.

Bệnh nhân được tái khám ở các thời điểm 1tháng và thời điểm kết thúc nghiên cứu tháng 
$5 / 2021$. Bảng 8 cho thây triệu chứng đường tiểu dưới cải thiện theo thời gian so với trước mổ, có 4 trường hợp hẹp niệu đạo sau phẫu thuật, trong đó3 trường hợp nong niệu đạo ổn định, 1 trường hợp phải mổ tạo hình niệu đạo, tại thời điểm kết thúc nghiên cứu có 1 trường hợp còn rối loạn tiểu tiện, nhiễm khuẩn niệu tái phát 1 trường hợp, trong thời gian theo dõi không có trường hợp nào phải nhập viện điều trị tim mạch hay can thiệp tim mạch, có 1 trường hợp tử vong do bệnh phổi tắc nghẽn mạn tính.

\section{KẾT LUÂ̂N}

Nội soi cắt tiền liệt tuyến qua đường niệu đạo bằng điện lưỡng cực là phương pháp an toàn và hiệu quả, giảm tai biến, biến chứng so với phương pháp đơn cực truyền thống, đặc biệt là trên nhóm bệnh nhân đồng mắc các bệnh lý tim mạch.

\section{TÀI LIỆU THAM KHẢO}

1. Kim E.H., Larson J.A., and Andriole G.L. (2016). "Management of Benign Prostatic Hyperplasia. Annu Rev Med, 67, 137-151.

2. Cleves $A_{.,}$Dimmock $P_{.,}$Hewitt N., et al. (2016). The TURis System for Transurethral Resection of the Prostate: A NICE Medical Technology Guidance. Appl Health Econ Health Policy, 14(3), 267-279.

3. Eagle K.A., Berger P.B., Calkins H., et al. (2002). ACC/AHA guideline update for perioperative cardiovascular evaluation for noncardiac surgery--executive summary: a report of the American College of Cardiology/American Heart Association Task Force on Practice Guidelines (Committee to Update the 1996 Guidelines on Perioperative Cardiovascular Evaluation for Noncardiac Surgery). J Am Coll Cardiol, 39(3), 542-553.

4. Albanesi L., Attisani F., Gentile B.C., et al. (2013). Comparative randomized study on the efficaciousness of endoscopic bipolar prostate resection versus monopolar resection technique. 3 year follow-up. Arch Ital Urol Androl, 85(2), 86-91.

5. Stucki P., Marini L., Mattei A., et al. (2015). Bipolar versus monopolar transurethral resection of the prostate: a prospective randomized trial focusing on bleeding complications. J Urol, 193(4), 1371-1375.

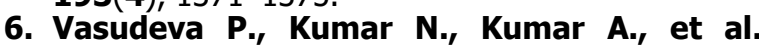
(2019). Impact of monopolar TURP, bipolar TURP and photoselective vaporization of prostate for enlarged prostate on erectile function. Low Urin Tract Symptoms, 11.(1), 24-29.

7. Trân Văn Hinh, Đố Ngọc Thể (2012). Đánh giá hiệu quả bước đầu của cắt đốt lưỡng cực tuyến tiền liệt qua nội soi niệu đạo. Y Dược lầm sàng 108 - 2013 - no.1 - tr.66-70 - ISSN.1859 -2872. .

8. Batra Y.K. and Bali I.M. (1978). Effect of coagulating and cutting current on a demand pacemaker during transurethral resection of the prostate. A case report. Can Anaesth Soc J, 25(1), 65-66.

9. Kellow N.H. (1993). Pacemaker failure during transurethral resection of the prostate. Anaesthesia, 48 (2), 136-138.

\title{
BƯớC ĐẦU ÁP DỤNG SIÊU ÂM TRộN ẢNH CộNG HƯởNG TỪ TRONG SINH THIẾT TUYẾN TIỀN LIẾT
}

\author{
Nguyễn Tuấn Anh ${ }^{1}$, Nguyễn Quốc Đạt ${ }^{2}$, Bùi Văn Giang ${ }^{1,2}$
}

\section{TÓM TẮT}

Mục tiêu: Đánh giá kết quả sinh thiết tuyến tiền liệt dưới siêu âm trộn ảnh cộng hưởng từ trong chẩn đoán ung thư tuyến tiền liệt. Đối tượng và phương pháp: Nghiên cưuu tiến cứu trên những bệnh nhân có chỉ định sinh thiết tuyến tiền liệt, được siểu âm tuyến tiền liệt đường trực tràng và chụp cộng hưởng tử tại bênh viện K3 từ tháng 6/2020 đển tháng 6/2021. Các tổn thương quan sát được trên MRI nhưng không quan sát rõ được trên siêu âm sẽ được áp dụng siêu âm trộn ảnh khi sinh thiết để lấy chính xác mâuu mô tương ứng với tổn thương trên MRI (MRI Fusion Biopsy). Tiến hành đối chiếu kết quả giải phẫu bệnh

\footnotetext{
${ }^{1}$ Trường Đại học Y Hà Nội

2Trung tâm Chẩn đoán hình ảnh - Bệnh viện K

Chịu trách nhiệm chính: Nguyễn Tuấn Anh

Email: bsntanh91@gmail.com

Ngày nhận bài: 2.6.2021

Ngày phản biện khoa học: 26.7.2021

Ngày duyệt bài: 3.8.2021
}

của hai phương pháp sinh thiết để nhận xét giá trị của sinh thiết đích dưới siêu âm trộn ảnh. Kết quả: 2 trường hợp bênh nhân đáp ứng tiêu chuẩn lựa chọn. Được sinhh thiểt đích dưới siêu âm trộn ảnh có kết quả giải phấu bệnh tương đương sinh thiết hệ thống. Kết luận: Sinh thiết đích dưới siêu âm trộn ảnh có giá trị tướng tự sinh thiết hệ thống tuyến tiền liệt trong chẩn đoán xác định ung thư tuyến tiền liệt.

Tư khóa: Ung thư tuyến tiền liệt, sinh thiết hệ thống, sinh thiết đích dưới siêu âm trộn ảnh cộng hưởng từ.

\section{SUMMARY}

\section{FIRST STEP APPLICATION OF MRI FUSION FOR GUIDANCE OF TARGETED PROSTATE BIOPSY}

Objective: To evaluate prostate biopsy results under ultrasound mixed magnetic resonance imaging in prostate cancer diagnosis. Subjects and methods: Prospective study on patients with indications for prostate biopsy, rectal ultrasound and magnetic resonance imaging at K3 hospital from June 